place for residents to raise families, share their culture, and, as this book reveals, find a voice to overcome challenges faced living in federal housing.

Jennifer Chutter

Simon Fraser University

\title{
Joanna Dreby, Everyday Illegal: When Policies Undermine Immigrant Families (Oakland, CA: University of California Press, 2015). 287 pp. \$29.95 Paper- back.
}

Everyday Illegal: When Policies Undermine Immigrant Families is a sequel to Joanna Dreby's 2010 book Divided by Borders: Mexican Migrants and their Children. In this new ethnographic contribution, Dreby conducted interviews with 110 children and 91 parents in New Jersey and Ohio to study the complex relational dynamics that develop within unauthorized Mexican immigrant communities. From the outset, Dreby importantly clarifies that this project does not represent all Mexicans living within both locations of interest and focuses on heteronormative family structures. Everyday Illegal demonstrates how, under the enforcement of restrictive US immigration law during the Obama administration, familial and peer dynamics are strained not only juridicially but also socially for immigrant families. It elucidates various interpersonal effects constituted and exacerbated by punitive US immigration policy, all of which may be overlooked through a merely legal understanding of unauthorized immigrant livelihood.

The culture of fear produced by punitive immigration policy is, Dreby argues, a serious public health concern. The threat of deportation has material effects on the anxiety levels of parents, especially those of unauthorized women who are susceptible to becoming what she terms suddenly single mothers. Illegality exposes mothers to ataques de nervios (anxiety attacks), for instance, which may also involve episodes of self-harm, as it does for one of Dreby's interviewees. Additionally, some migrant children who were interviewed described having regularly faced educational barriers, lack of access to adequate healthcare, and food insecurity. The recent rise of these severe social effects in the US are correlated, for Dreby as well as for many other scholars, to the post-9/11 creation and continuing expansion of the Department of Homeland Security's enforcement procedures.

Dreby's study also shows how legal-status differences bolster daily experiences of gender inequality for women. These dynamics of illegality augment the abusive social conditions within which many unauthorized women already find themselves, especially with the rapid emergence of mixed-status families in the US (mixed-status families are those consisting of authorized and unauthorized members). As Dreby's field work as well as personal experiences with mixed-status familial life suggest, legalization is closely linked for some immigrant men to patriarchal conceptions of masculinity, where both legal status and a lack thereof 
may be employed to justify a re-centering of male domination within the household. This can be seen even within mixed-status families that include citizen women, where an unauthorized husband may experience illegality as a threat to his masculinity, in turn demanding an even more rigid domestic commitment from his wife and female-designated children to accomplish household labour.

Dreby's interviews with children comprise some of the most memorable moments in Everyday Illegal. Restrictive immigration policy, she argues, is a source of stigma in children's relationships with parents, siblings, and other children. For instance, Dreby interviewed children who candidly describe the stresses of having to act as cultural brokers for their parents, often serving as family translators. Accounts of discriminatory bullying experienced by the children of unauthorized parents further elucidate the detrimental complexities of their peer relations. Data too shows that pecking orders among siblings within mixed-status families are intensified when some have more access to legal, economic, and educational resources than others. These ethnographic analyses in turn lead to what is perhaps Dreby's most significant theoretical and methodological contribution in the book; that is, that the administrative and legal privileges denied to unauthorized immigrants converge upon the category of illegality "to accrue a social significance similar to that of racial or class background." (103) This strain of social significance attached to illegality is best understood from the ground up, particularly from the voices of the children who suffer under punitive US immigration policy.

Dreby devotes an appendix to a thorough review of the measures taken to ensure the ethical treatment of her underage interviewees, and even includes her interview schedules. Moreover, she leaves readers, in the book's conclusion, with the words of children on the topic of president Barack Obama's presidency, centralizing their often-disregarded capacity for political critique. Everyday Illegal is not only a timely contribution but a detailed, deftly narrated, and unique one that exposes the alarming extent to which citizen and unauthorized children living under unauthorized parents daily confront the strenuous social repercussions of restrictive immigration policy as intensely, if not more so, as their caretakers. Indeed this book is an important resource for all scholars interested in the multifaceted ways in which families experience social rupture under the US regime of illegality.

Caleb Lázaro Moreno University of Kansas 